\title{
The Anatomy of Circulus Arteriosus Cerebri (Circle of Willis): A Study in Turkish Population
}

\author{
Ayse KARATAS 1,2, Hakan YILMAZ³, Gokmen COBAN³ ${ }^{3}$ Murat KOKER ${ }^{4}$, Aysun UZ² \\ ${ }^{1}$ Izmir Katip Celebi University, Ataturk Education and Research Hospital, Department of Neurosurgery, Izmir, Turkey \\ ${ }^{2}$ Ankara University, School of Medicine, Department of Anatomy, Ankara, Turkey \\ ${ }^{3}$ Bozyaka Education and Research Hospital, Department of Neurosurgery, Izmir, Turkey \\ ${ }^{4}$ Forensic Medicine Institute, Izmir, Turkey
}

\section{ABSTRACT}

AIM: The function of the circle of Willis, an arterial polygon, is to protect the brain from ischemia. The aim of this study is to define the structural characteristics of the circle of Willis within the Turkish adult population, along with variations and arteries involved in the measurement of diameters and lengths on cadavers.

MATERIAL and METHODS: The circle of Willis was evaluated in 100 fresh adult cadavers. Structures of the circle of Willis were evaluated as being typical or atypical images and according to the diameter of AComP. All arteries forming the circle's length and diameters were measured.

RESULTS: All arteries forming the circle of Willis as $91 \%$ were anatomically observed. The typical structure in which hypoplasia arteries is not involved was obtained as $8 \%$. The atypical circle of Willis with aplasia was seen as $9 \% .87 \%$ of adult, $9 \%$ fetal, and $4 \%$ transitional configuration in the samples were detected. The variations of the circle of Willis were more common in the posterior portion. Hypoplasia was found to be the most common variation and noted as a maximum in AComP (85\%). Aplasia was noted as the second most common variation after hypoplasia and again the most common in AComP (5\%).

CONCLUSION: Advances in radiological methods which provide images of cerebral vessels and the development of cerebrovascular surgery have increased the importance of the circle of Willis in neurosurgery and neurology. The structure of the circle of Willis is of great importance in occlusive cerebrovascular diseases and cerebrovascular surgery.

KEYWORDS: Neuroanatomy, Neurovascular, Cerebral arterial circle, Willis polygon, Variation

\section{INTRODUCTION}

Circulus arteriosus cerebri was defined by Thomas Willis in 1664 and is referred to by his name $(12,25)$. The circle of Willis is an artery polygon, a vascular ring composed of branches of arteria (a) carotis interna and a. basilaris around infundibulum and chiasma opticum in cisterna interpedunculus in the brainstem and anastomoses between them. Vessels forming the circle of Willis are as follows: bilateral a. cerebri anterior (ACA) and a. communicans anterior (AComA) which links these two arteries, bilateral artery cerebri posterior (ACP), a. communi- cans posterior (AComP) which links a. carotis interna $(\mathrm{ACl})$ to ACP and a basilaris in anterior middle part. ACls, ACAs, AComA and their branches are defined as "anterior circulation/carotis system", ACPs, AComPs, a.vertebralis and a. basilaris are defined as "posterior circulation/vertebrobasilar system" (22).

The circle of Willis, whose function is to protect the brain from ischemia, is the main structure that provides constant and regular blood flow to the brain. Despite the presence of detailed studies concerning each of the vessels that constitute 
(A)

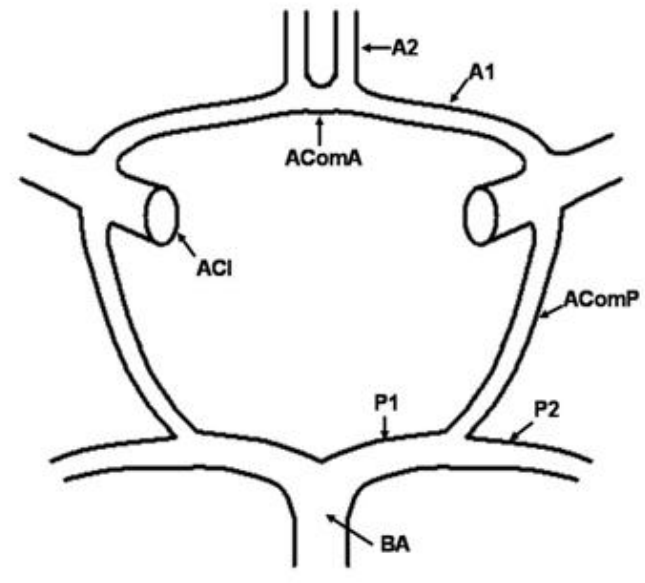

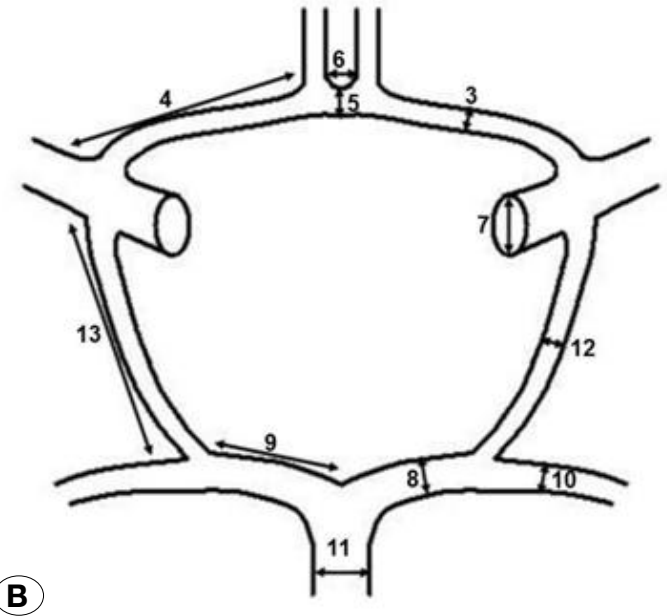

Figure 1: A) Schematic drawing illustrating the components of circle of Willis, B) indicating the numerical label of measured parameters (A1: Arteria Cerebri Anterior (ACA) A1 segment, A2: Arteria Cerebri Anterior (ACA) A2 segment, ACl: Arteria Carotis Interna, AComA: Arteria Communicans Anterior, AComP: Arteria Communicans Posterior, P1: Arteria Cerebri Posterior P1 segment, P2: Arteria Cerebri Posterior P2 segment, BA: Arteria Basilaris).

the polygon, studies regarding the whole of circle are relatively sparse. In addition, no studies are available in the literature investigating the circle of Willis within the adult Turkish population. The aim of this study was to determine structural characteristics of the circle of Willis in order to detect its variations and measure the diameter and length of the arteries that contribute to this structure in cadavers in the Turkish population.

\section{MATERIAL and METHODS}

This study was carried out on 100 adult fresh cadavers at Izmir Forensic Medicine Institution with the permission of the Presidency of the Scientific Board of Council of Forensic Medicine (Approval number: B.03.1.ATK.0.01.00.08/142). The study group consisted of 19 females (19\%) and 81 males (81\%), and the mean age was 55.33 years (range 16-95). The study group consisted of 65 adults (16-64 years) and 35 elderly people (65-95 years). Central nervous system diseases were excluded from the study. After being dissected with the microsurgery technique, the diameter and length of the arteries that constituted the circle of Willis were measured using a caliper (BTS Digital Calippar 150x0.01 mm) with sensitivity of $0.1 \mathrm{~mm}$ and and photographed with a digital camera (Sony, 7.2 megapixels).

The following parameters were evaluated. The parameters of rows 3-13 are schematized in Figure 1.

1. The structure of the circle of Willis (a typical image means that all of the arteries forming the circle show no hypoplasia and an atypical image means aplasia is present)

2. The structure of circle of Willis according to the diameter of AComP (Adult configuration; diamater of AComP smaller than P1. Fetal configuration: diamater of AComP larger than P1. Transitional configuration: diamater of AComP same as $\mathrm{P1}$ )
3. The diameter of ACA (A1) (right-left)

4. The length of $A C A(A 1)$ (right-left)

5. The diameter of AComA

6. The length of $A C o m A$

7. The diameter of $\mathrm{ACl}$ (right-left)

8. The diameter of PCA (P1) (right-left)

9. The length of PCA (P1) (right-left)

10. The diameter of PCA (P2) (right-left)

\section{The diameter of A.basilaris}

12. The diameter of AComP (right-left)

13. The length of AComP (right-left)

14. The variations (Absence of artery was evaluated as aplasia, diameter of artery smaller than $1 \mathrm{~mm}$ was evaluated as hypoplasia)

Data were transferred to the SPSS 20 (Statistical Packages for Social Sciences) program for statistical analysis. The Wilcoxon test was used for comparing right and left. Statistical significance was established according to corrected nominal alpha values relating to the Bonferroni method. A multivariate analysis of variance (MANOVA) was implemented to compare age groups across the listed variables. The multivariate test (Pillai's trace) did not indicate a statistically significant group difference and therefore no follow-up tests were required.

\section{RESULTS}

All of the arteries forming the circle of Willis were found in 91 samples (91\%). Typical (complete-normal) polygonal structures included all the arteries forming the circle but hypoplas- 
tic arteries were not evaluated as they were noted in just 8 samples (8\%) (Table I).

An atypical circle of Willis (incomplete-abnormal) which included aplastic arteries was found in 9 samples (aplasia in 2 anterior, 7 posterior system) (9\%) (Table I).

According to the relationship between AComP and P1 diamaters, adult configuration was detected in 87 samples $(87 \%)$ (Figure 2). Fetal configuration was detected in 9 (9\%) and transitional configuration was detected in $4(4 \%)$ (Table II) (Figure 3).

Variations of anterior and posterior parts of the circle of Willis are summarized in Tables III, IV. Variations were found more in the posterior section. Hypoplasia is the most common variation and was found to be most common in AComP (85\%). Aplasia is the second leading variation and was also detected in AComP (5\%). AComA hypoplasia is the most common variation seen in anterior part (20\%). Hypoplasia was found to

Table I: The Number and Rate of Forming the Circle of Willis Arteries

\begin{tabular}{ll}
\hline Typical polygon (without aplasia) & $91(91 \%)$ \\
\hline Typical polygon (without hypoplasia) & $8(8 \%)$ \\
\hline Atypical polygon (with aplasia) & $9(9 \%)$ \\
\hline Anterior segment & 2 \\
\hline Posterior segment & 7 \\
\hline Anterior-Posterior & - \\
\hline
\end{tabular}

Table II: The Number and Rate of Adult, Fetal and Transitional Configuration

\begin{tabular}{cc}
\hline Adult configuration & $87(87 \%)$ \\
\hline Fetal configuration & $9(9 \%)$ \\
\hline Right & 4 \\
\hline Left & 4 \\
\hline Bilateral & 1 \\
\hline Transitional configuration & $4(4 \%)$ \\
\hline
\end{tabular}

be the most common in AComA following AComP. The most common multiple variation is the coexistence of AComA and AComP hypoplasia which was found in 16 samples (16\%) (Figure 4).

When results were evaluated according to age groups, although it is not a balanced number of samples with only AComA and AcomP, hypoplasia was found to be statistically higher among the elderly group $(\mathrm{p}<0.05)$.

Diameter and length measurements along with mean values and ranges of the arteries are presented in Table $\mathrm{V}$.

In values presenting bilateral measurement; the difference between right and left was found only in A1 length. The right A1 was found to be significantly longer than the left.

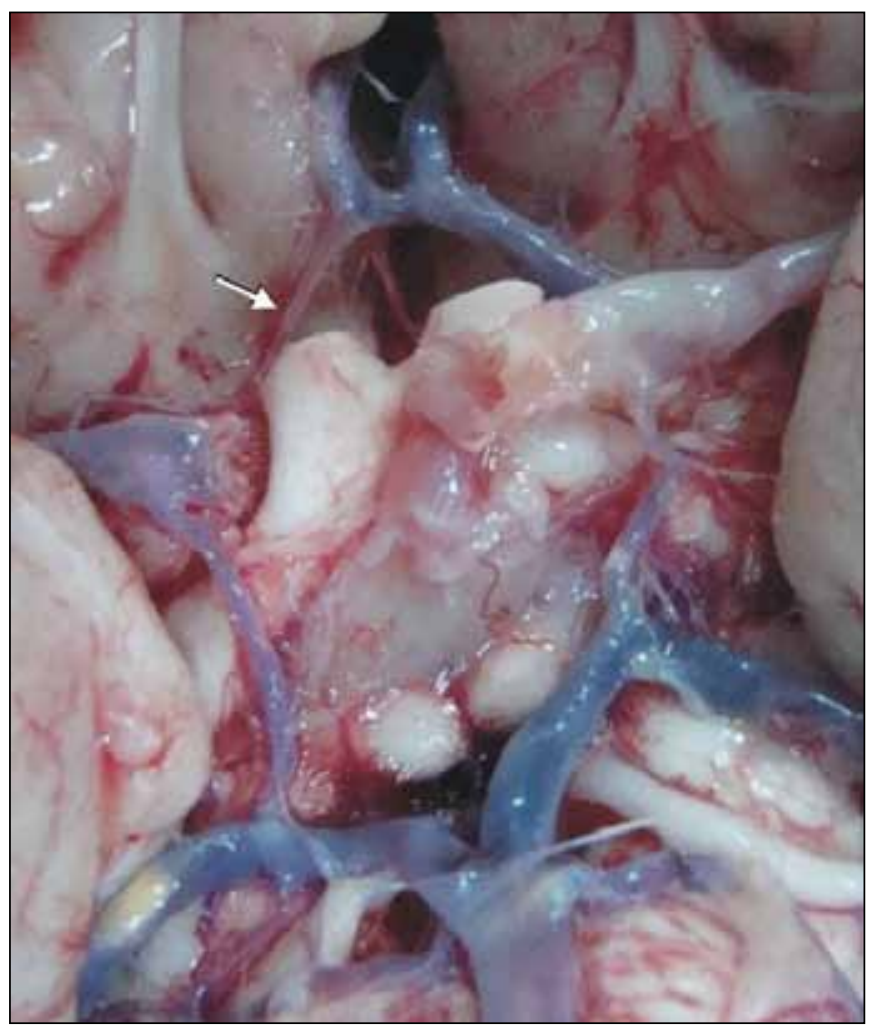

Figure 2: Right A1 hypoplasia, adult configuration (Arrow is showing hypoplastic right $A 1)$.

Table III: The Number and Rate of Variations of Anterior Part of the Circle of Willis Arteries

\begin{tabular}{lcccccc}
\hline Variations & & & & \\
& Single & Combined & Right & Left & Combined & Total \\
\hline AcomA aplasia & & & & Right & Left \\
\hline AcomA hypoplasia & - & 1 & & & $1(1 \%)$ \\
\hline A1 aplasia & 2 & 18 & & & $20(20 \%)$ \\
\hline A1 hypoplasia & & & - & 1 & - & $1(1 \%)$ \\
\hline
\end{tabular}


Table IV: The Number and Rate of Variations of Posterior Part of the Circle of Willis Arteries

Variations

Incidence

\begin{tabular}{lccccccc}
\hline & Right & Left & Bilateral & \multicolumn{2}{c}{ Combined } & \multicolumn{2}{c}{ Total } \\
\hline & & & & Right & Left & Bilateral & \\
\hline AcomA aplasia & 1 & - & - & 2 & 1 & 1 & $5(5 \%)$ \\
\hline AcomA hypoplasia & 8 & 16 & 37 & 9 & 4 & 11 & $85(85 \%)$ \\
\hline A1 aplasia & - & - & - & - & 2 & - & $2(2 \%)$ \\
\hline A1 hypoplasia & - & - & 1 & 1 & - & - & $2(2 \%)$ \\
\hline
\end{tabular}

Table V: The Average, Minimum and Maximum Values of Arteries Diameter and Length (SS: standard deviation).

\begin{tabular}{|c|c|c|c|c|}
\hline \multirow[t]{2}{*}{ Arteries } & \multicolumn{2}{|c|}{ Diameter Mean \pm SD $(\mathrm{mm})$} & \multicolumn{2}{|c|}{ Length Mean \pm SD $(\mathrm{mm})$} \\
\hline & Right & Left & Right & Left \\
\hline ACA (A1 & $1.87 \pm 0.48(0.30-3.40)$ & $1.96 \pm 0.49(1.00-3.20)$ & $14.44 \pm 2.32(8.10-20.00)$ & $13.72 \pm 2.12(8.30-19.50)$ \\
\hline AComA & $1.43 \pm 0.60(0.20-3.70)$ & $1.95 \pm 0.97(0.40-4.90)$ & & \\
\hline $\mathrm{ACl}$ & $3.55 \pm 0.65(2.30-5.80)$ & $3.45 \pm 0.64(2.00-5.00)$ & & \\
\hline $\mathrm{ACP}(\mathrm{P} 1)$ & $1.91 \pm 0.56(0.60-3.50)$ & $1.96 \pm 0.52(0.80-3.20)$ & $6.09 \pm 1.82(3.20-14.30)$ & $6.04 \pm 1.54(3.20-11.90)$ \\
\hline $\mathrm{ACP}(\mathrm{P} 2)$ & $1.92 \pm 0.51(0.90-4.20)$ & $1.92 \pm 0.48(1.00-3.10)$ & & \\
\hline A.basilaris & $3.61 \pm 0.65(1.90-5.30)$ & & & \\
\hline AComP & $0.90 \pm 0.39(0.30-2.30)$ & $0.90 \pm 0.36(0.30-2.20)$ & $15.49 \pm 3.18(10.00-25.70)$ & $15.08 \pm 3.11(8.60-24.70)$ \\
\hline
\end{tabular}

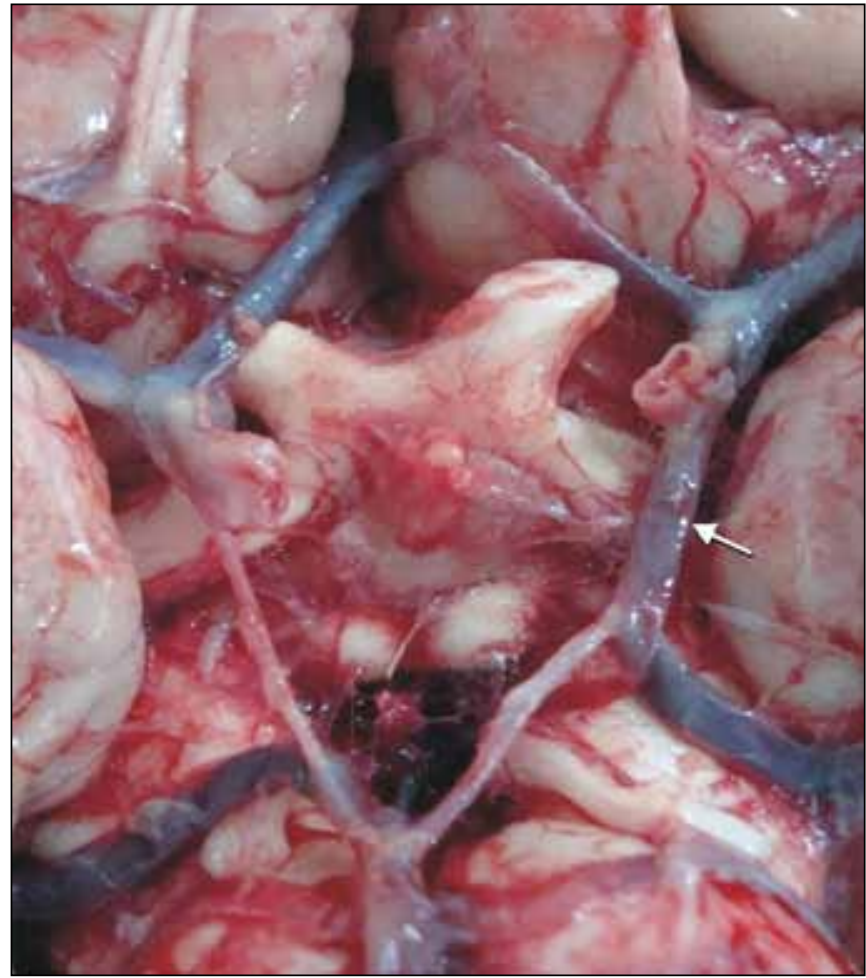

Figure 3: Left fetal configuration (Arrow is showing fetal originated AComP).

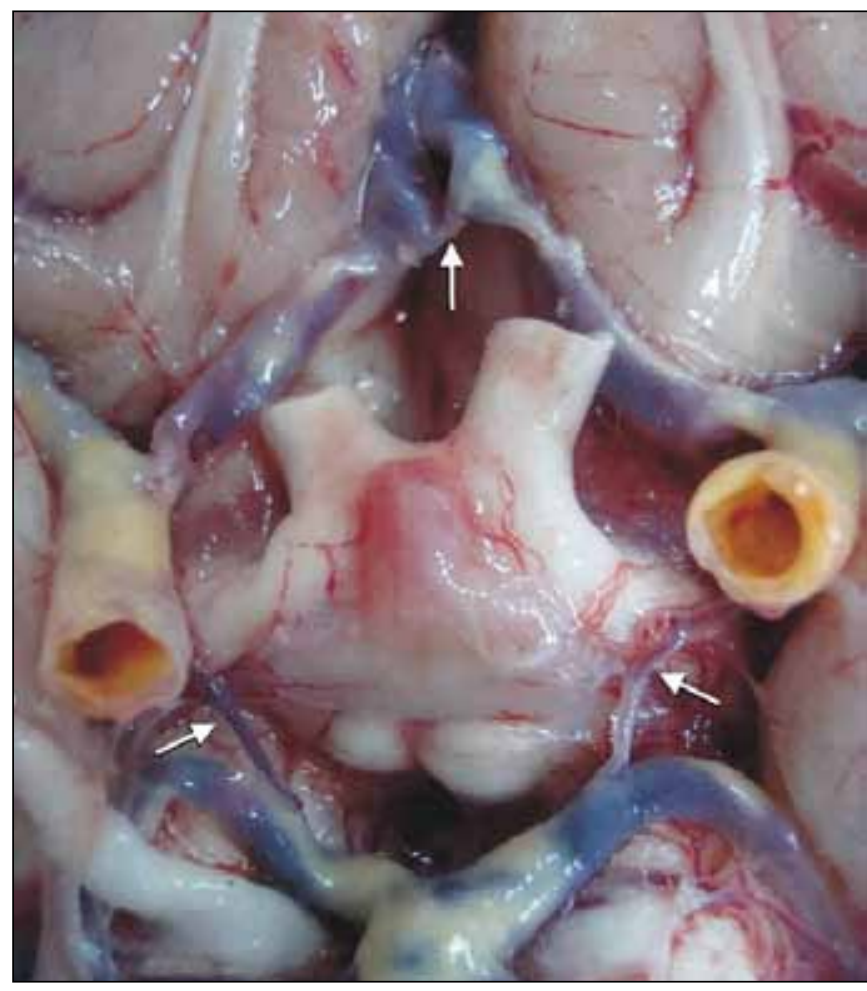

Figure 4: Bilateral AComP hypoplasia and AComA hypoplasia (Arrows are showing hypoplastic right and left AComP and AComA). 


\section{Arteria carotis interna}

The mean $\mathrm{ACl}$ diameter was measured as $3.55 \pm 0.65 \mathrm{~mm}$ on the right and $3.45 \pm 0.64 \mathrm{~mm}$ in the left. No variations were detected.

\section{Arteria cerebri Anterior (A1)}

A1 length was measured as $14.44 \pm 2.32 \mathrm{~mm}$ in the right and $13.72 \pm 2.12 \mathrm{~mm}$ in the left. The right $A 1$ was found to be significantly longer. A1 diameter was measured as $87 \pm 0.48 \mathrm{~mm}$ in the right and $1.96 \pm 0.49 \mathrm{~mm}$ in the left. In the right, combined (together with other variations) 2 hypoplasia and 1 aplasia were detected in A1. Variation was not noticed in the left A1.

\section{Arteria communicans anterior}

The mean length of AComA was measured as $1.95 \pm 0.97 \mathrm{~mm}$, diameter as $1.43 \pm 0.60 \mathrm{~mm}$. Twenty (2 single, 18 combined variations) hypoplasia and 1 combined aplasia and 1 duplication were detected. Hypoplasia was detected in $14 \%$ of adults, in $31 \%$ of the elderly groups.

\section{Arteria communicans posterior}

The length of AComP was measured as $15.49 \pm 3.18 \mathrm{~mm}$ in the right and $15.08 \pm 3.11 \mathrm{~mm}$ in the left. AComP diameter was found to be $0.90 \pm 0.39 \mathrm{~mm}$ in the right and $0.90 \pm 0.36 \mathrm{~mm}$ in the left. A total of 85 hypoplasia (8 right, 16 left, 37 bilateral, 24 combined) and 5 aplasia (1 right, 4 combined) were detected in AComP. Hypoplasia was detected among $60 \%$ of adults, and $83 \%$ of the elderly groups.

\section{Arteria cerebri posterior}

ACP (P1) length was measured with a mean $6.09 \pm 1.82 \mathrm{~mm}$ in the right and $6.04 \pm 1.54 \mathrm{~mm}$ in the left. $\mathrm{P} 1$ diameter was measured as $1.91 \pm 0.56 \mathrm{~mm}$ in the right and $1.96 \pm 0.52 \mathrm{~mm}$ in the left. P1 hypoplasia was detected 1 bilateral and $1 \mathrm{com}-$ bined (right). P2 aplasia was detected as 2 combined anomalies (left). ACP (P2) diameter was measured as $1.92 \pm 0.51 \mathrm{~mm}$ in the right and $1.92 \pm 0.48 \mathrm{~mm}$ in the left.

\section{Arteria basilaris}

Mean a. basilaris diameter was measured as $3.61 \pm 0.65 \mathrm{~mm}$. No variations were detected.

\section{DISCUSSION}

Circulus arteriosus cerebri is in fact not a real circle and is more of a nonagon with 9 borders ( 3 anterior, 2 anterolateral and 4 posterior) (22). A complete circle of Willis is composed of 10 arterial parts. A complete circle that does not have hypoplastic arteries is seen in less than half of the cases and the rate is reported in a large range as $4.6-72.2 \%(2,3,4,8,11)$. The cause of this wide range is considered to be differences in the definition and hypoplasia criteria, along with the inability to make real measurements in the studies.

Variations of the circle of Willis are more frequent in the posterior part and most common in AComP $(1,19,22,26)$. Variations have been reported more frequently cerebrovascular diseases, cerebral aneurysm and mental diseases $(1,14,16,24,27)$. According to Padget, the circle of Willis is formed at 6-7. weeks of gestation (24). It was reported that all segments of the circle are thin and with the same diameter in a 4 month fetus, while differences are seen in segment diameters in fetuses older than 4 months $(17,19,24)$. Variations may develop out of normal polygon structure. When and why these variations develop is not clear. Causes of variations in the circle of Willis, when they developed and why they are present in fetal life have been studied by various study groups $(5,17,23)$. Comments available report that they are present in fetal life $(5,18,19,28)$ or develop after birth $(13,17)$.

Padget divided the circle of Willis into three configurations according to the diameters of AComP and ACP (24). Adult configuration; diamater of AComP smaller than P1. Padget, reported this configuration as less than $50 \%$. Fetal configuration, with a diameter of AComP larger than P1 and the main vascularization of the occipital lobe are provided by ACl. Transitional configuration, with a diameter of AComP is the same as $\mathrm{P} 1$.

Adult configuration was noticed among adults in the following studies: Riggs and Rupp, 76\%; Kamath, 73.5\%; Yasargil, 67.5\%; Zeal and Rhoton, 58\%; Saeki and Rhoton, 54\% $(14,26,27,30,31)$. In the present study this configuration was found to be $87 \%$.

Fetal configuration was noticed among adults as follows; Zeal and Rhoton, 40\%, Kamath, 25\%, Yasargil, 24,5\%, Saeki and Rhoton, 22\%, Riggs and Rupp, 17\%, Alpers and Berry, 15\% $(1,14,26,27,30,31)$. In the present study $9 \%$ fetal configuration was found.

Transitional configuration was noticed among adults as follows; Yasargil, 8\%, Riggs and Rupp, 7\%, Zeal and Rhoton, $2 \%$, Kamath, $1.5 \%(14,26,30,31)$. In the present study $4 \%$ transitional configuration was found.

Typical polygonal structure, which includes all arteries forming the circle of Willis and hypoplasia not present has been obtained in $8(8 \%)$ samples. Atypical circle including aplasia was found in 9 (2 anterior and 7 posterior systems) (9\%) samples. Aplasia was found to be most common in posterior circulation and AComP.

Fawcet and Blachford reported normal polygon in the ratio of $72.8 \%$ in their series of 700 autopsies and detected aplasia in the ratio of $3.8 \%$ (most common in AComP) (10).

In autopsy studies conducted with normal brains of 350 cases by Alpers et al. (age range between newborn period and 88 years), while normal polygon was found with the ratio of $52 \%$, an atypical polygon ratio was reported as $0.6 \%$ due to left AComP aplasia. Hypoplasia was most common in AComP with the ratio of $22 \%$ ( $8 \%$ unilateral, $6 \%$ bilateral, $8 \%$ together with other anomalies). AComA was more than one in $9 \%$, triplication was detected in ACA in $8 \%$ cases. Fetal AComP was found to be $15 \%$ ( $5 \%$ unilateral, $4 \%$ bilateral, $6 \%$ combined). Multiple anomaly was detected in 13\% (2).

In the study carried out by Alpers and Berry the normal polygon was found to be $52 \%$. They reported this ratio as $33.91 \%$ in the study conducted with 194 cerebral infarction cases due to embolism or thrombus, this ratio was reported as $37 \%$ in 
aneurysm cases (1). The authors reported hypoplastic vessels as the most common anomaly observed in the circle of Willis. Hypoplasia was found to be most common in AComP $(22 \%$ in normal brains, $38 \%$ in brains with infarction and $40 \%$ in brains with aneurysm). AComP aplasia was found as $0.6 \%$ in normal brains, $1.5 \%$ in brains with infarction and $3 \%$ in brains with aneurysm. Fetal AComP was found to be $15 \%$ in normal brains, $29 \%$ in brains with infarction and $22 \%$ in brains with aneurysm. In conclusion, AComP hypoplasia, aplasia and fetal AComP were found to be higher among patients with cerebral occlusive disease and aneurysm compared to normal patients. The circle of Willis insufficiency is reported in vasoocclusive diseases, in presence of partial or total occlusion of other arteries in the absence of one AComP. However there is no a clear explanation regarding the role of hypoplasia alone in the development of infarction $(1,2)$.

Wilson et al. showed one A1 hypoplasia in $85 \%$ of AComA aneurysms. It was reported that hemodynamic anomaly contributed to aneurysm formation, while a strong correlation was reported between hypoplastic segments and aneurysm (29).

A typical polygon was detected in $21 \%$, and hypoplasia in $79 \%$ in the study by Riggs and Rupp, which was conducted on 994 adult autopsy series with neural dysfunction (26). Neurologic disorders were associated with an impaired blood flow developing due to hypoplasia. Hypoplasia was detected most commonly in AComP followed by AcomA, while a fetal configuration was detected in 54 cases (5\%) (26).

Arteria communicans smaller than $0.5 \mathrm{~mm}$ and other arteries smaller than $1 \mathrm{~mm}$ were accepted as abnormal in the study of Kamath reported with 100 cadavers in India (14). The most common anomaly was detected in ACP and AComP. The most common variation in length was detected in AComA and the most common variation in diameter was detected in AComP. Longer and smaller arteries were found in the right half of the polygon. Blood flow was found to be more effective in short thick arteries, while the left hemisphere was explained as being supplied better (14).

While no difference was noted between males and females, arteries in the left were found to be longer than the right in the study of Orlandini et al. conducted with 100 Italian cadavers (17-84 years) (21). The impaired structure in the circle of Willis was reported as being caused by AComA and AComP (21).

In the study of Eftekhar et al. conducted with 102 male autopsy cases aged between 15-75 years among the Iranian population the circle of Willis was evaluated by measuring with digital photographs and the typical circle of Willis was detected as being in the ratio of $28 \%$ (9). Aplasia was not found in $\mathrm{A} 1$ and $\mathrm{P} 1$ segments, hypoplasia was not found in the left $A 1,1 \%$ hypoplasia was found in the right $\mathrm{A} 1,11 \%$ hypoplasia and $1 \%$ aplasia was found in AComA. In AComP, 16\% hypoplasia was detected in the right, $11 \%$ hypoplasia was detected in the left and $33 \%$ bilateral hypoplasia was detected. In AComP, 4\% aplasia was detected in the right, 3\% aplasia was detected in the left and bilateral aplasia was detected in $3 \%$. In $27 \%$ cases the diameter of P1 was found to be smaller than AComP (fetal). A significant difference was not detected compared to the studies conducted in other races despite the limitation of the study (9).

The circle of Willis was analysed in 225 autopsy cases aged between 18-73 in De Silva et al., conducted among the Sri Lankan population (8). In this study, the circle which had all parts and artery diameters $>1 \mathrm{~mm}$ was defined as "typical", arteries smaller than $1 \mathrm{~mm}$ in diameter were accepted as "hypoplastic". Typical polygon was detected in $14.2 \%$ of cases, variation was seen in posterior part in $70 \%$ of cases. $13.5 \%$ unilateral hypoplasia, $51.5 \%$ bilateral hypoplasia was detected in AComP, 3.8\% unilateral hypoplasia, 1.6\% bilateral hypoplasia was detected in $\mathrm{P} 1,25 \%$ hypoplasia was detected in AComA, 4.1\% unilateral hypoplasia was detected in A1 (10). A typical circle of Willis ratio was detected as $52 \%$ in the study conducted in USA (2) and $45.2 \%$ in the study conducted in India (15). The immense difference between results among the Sri Lankan and Indian population was considered to be related to genetic, racial, regional, environmental, hemodynamic factors, or a combination of these despite their common origin, and it was stated that the influence of these factors should be investigated. The frequency of stroke in posterior circulation is greater among people from Asian races compared to the west. The cause of this could not be fully explained and the role of anatomic and pathologic properties of cerebral arteries in different races could not be established (8).

Typical polygon was observed in the ratio of $45.2 \%$ in the autopsy study of Kapoor et al, reported with 1000 cases among different ages in India (15). Cases which included all parts and no variation or hypoplasia were accepted as typical. Variation was found in the ratio of $23.4 \%$ in anterior and $31.4 \%$ in posterior. A1 aplasia was found to be $0.4 \%$, hypoplasia $1.7 \%$ and duplication $2.6 \% .1 .8 \%$ aplasia and $10 \%$ duplication was detected in AComA. 10.6\% hypoplasia (fetal) was detected in $\mathrm{P} 1,1 \%$ aplasia and $16.7 \%$ hypoplasia was detected in AComP. Multiple variations were detected in the brain in the ratio of $7.4 \%(15)$.

In the literature, measurements of a normal polygon have been reported as follows: A1 diameter $2.6 \mathrm{~mm}$ (0.9-4.0), length 12.7 $\mathrm{mm}$ (7.2-18.0), AComA diameter $1.5 \mathrm{~mm}(0.2-3.4)$, length 2.6 $\mathrm{mm}$ (0.3-7.0), ACl diameter $4.3 \mathrm{~mm}$ (2.5-7.0), P1 diameter 2.6 $\mathrm{mm}(0.9-4.0)$, length $7.0 \mathrm{~mm}(3.0-20)$, P2 diameter $2.7 \mathrm{~mm}$ (1.6-4.0), a. basilaris diameter $4,1 \mathrm{~mm}$ (3.0-5.5), AComP diameter $1.3 \mathrm{~mm}$ (0.3-3.1), length $12.6 \mathrm{~mm}$ (7.0-23) (27). In our study, diameters and lengths of arteries were found to be consistent with the literature and these results were not discussed separately.

All of the arteries forming the circle of Willis polygon were found to be present iat a rate of $91 \%$ in the present study. The typical polygonal structure in which all arteries were present but hypoplastic arteries were not observed was found to be $8 \%$. The rate of an atypical circle of Willis with aplasia was $9 \%$. Adult configuration was detected as $87 \%$, fetal as $9 \%$ and transitional $4 \%$. In this study AComP hypoplasia was found to be higher compared to the literature, thereby the typical polygon ratio in which hypoplastic arteries were not included was detected as low. The probable reason for the wide range of typical polygon ratio in the literature may be due to differ- 
ences relating to criteria and defining hypoplasia. However, further studies are necessary to confirm the influence of genetic, racial, environmental and hemodynamic factors. Finding adult configuration greater than in the literature, and fetal configuration lower than in the literature was explained by a greater AComP hypoplasia and lower P1 hypoplasia ratio.

The circle of Willis variations were found to be more in the posterior part, which is consistent with the literature. The most common variation is hypoplasia, a condition seen most commonly in AComP (85\%). This hypoplasia was $24 \%$ unilateral, $37 \%$ bilateral and $24 \%$ together with other anomalies. Aplasia, the second leading variation following hypoplasia, was also found to be most common in AComP (5\%). The second most common hypoplasia site is AComA (20\%). AComA hypoplasia was found to have the most variation in the anterior part. The most common multiple variation is AComA and AcomP hypoplasia coexistence which was found in the ratio of $16 \%$.

The $\mathrm{A} 1$ and $\mathrm{AComA}$ aplasia rate was $1 \%$, and $\mathrm{P} 1$ aplasia rate $2 \%$. The $A 1$ and $P 1$ hypoplasia rate was $2 \%$. The A1, AComA, AComP and $\mathrm{P} 1$ aplasias and $\mathrm{A} 1, \mathrm{AComA}$ hypoplasia rates were found to be consistent with the literature. The rate of AComA duplication, which is among the rare variations, was $1 \%$ in our study, lower than the literature.

In values measured bilaterally, only the right $A 1$ was found to be significantly longer than the left, a result consistent with Kamath (14).

According to the results of our study, the circle of Willis variations were found to be more common in the posterior circulation, which is consistent with the literature on the adult Turkish population. The most common variation was hypoplasia and this condition was seen most commonly in the AComP. AComP hypoplasia was found to be more common compared to the literature, where the typical polygon ratio in which hypoplastic arteries were not included was detected as low. The second most common hypoplasia site was AComA. AComA hypoplasia was found to have the most variation in the anterior part. The most common multiple variation was $A C o m A$ and AcomP hypoplasia coexistence. The rates of $A 1, A C o m A$, AComP and $P 1$ aplasias and $A 1, A C o m A$ hypoplasias were found to be consistent with the literature. The rate of a AComA duplication, which is among the rare variations, was $1 \%$ in our study, lower than in the literature. Finding the adult configuration rate greater than in the literature and the fetal configuration rate lower than in the literature may be explained by the greater AComP hypoplasia and lower P1 hypoplasia rates. The potency and size of the arteries in the circle of Willis is important in occlusive cerebrovascular diseases and cerebrovascular surgery. Although variations are common, most do not lead to clinical problems because of the colleteral anastomotic polygon. However, the presence of a hypoplastic or aplastic AComP is an independent risk factor for ischemic cerebral infarction when the $\mathrm{ACl}$ is occluded (22). AComP is the longest segment of the circle of Willis in which size is important for tolerance to ischemia. Chuang et al. demonstrated that AComP hypoplasia appears to be a contributor to the risk of ischemic stroke, even in the absence of $\mathrm{ACl}$ occlusion (6). Miyazawa et al. also found a higher frequency of lacunes in the basal ganglia among patients with hypoplasia or aplasia in the anterior part of the circle of Willis (20). Recovery level of patients in occlusive vascular diseases may be explained with some variations in the circle of Willis. Chuang et al. found that patients with a complete circle of Willis were more likely to have early improvement than the incomplete group in ischemic stroke patients (7). Stroke is one of the most serious cerebrovascular diseases in Turkey, and the frequency of stroke in the posterior circulation is greater among people from Asian races compared to the west. The AComP hypoplasia rate was found to be higher compared to the literature in the adult Turkish population. The reason could be related to racial aspects. Further studies are needed to look into the role of anatomic properties of the circle of Willis and their effect on the frequency of stroke, especially in the posterior circulation, in Turkey.

\section{- CONCLUSION}

The variations of the circle of Willis were found to be more common in the posterior circulation, which is consistent with the literature relating to the adult Turkish population. The AComP hypoplasia was found to be more common compared to the literature, where the typical polygon ratio was detected as low. The reasons may be related to racial factors. Further studies are necessary to confirm the influence of genetic, racial, environmental and hemodynamic factors or the combination of these components on the circle of Willis. Apart from studies of the healthy population, the clinical implications of variations of the Willis polygon should be examined through studies of a large number of patients with cerebrovascular disorders.

\section{- REFERENCES}

1. Alpers BJ, Berry RG: Circle of Willis in cerebral vasculer disorders. Arch of Neurol 8: 68-72, 1963

2. Alpers BJ, Berry RG, Paddison RM: Anatomical studies of the circle of Willis in normal brain. Arch Neurol Psychiat 81: 409-418, 1959

3. Baptista AG: Studies on the arteries of the brain. Acta Neurol Scand 40: 398-414, 1964

4. Battacharji SK, Hutchinson EC, Mc Call AJ: The circle of Willis the incidance of developmental abnormalities in normal and infarcted brains. Brain 90: 747-758, 1967

5. Büyükmumcu $M$, Karabulut $A$, Şeker $M$, Ziylan $T$, Salbacak $A$, Erongun U: Insan fötüslarında Willis poligonuna ait varyasyonların araştırıması. Türk Nöroşirürji Dergisi 9: 12-18, 1999 (In Turkish)

6. Chuang YM, Liu CY, Pan PJ, Lin CP: Posterior communicating artery hypoplasia as a risk factor for acute ischemic stroke in the absence of carotid artery occlusion. J Clin Neurosci 15:1376-81, 2008

7. Chuang YM, Chan L, Lai YJ, Kuo KH, Chiou YH, Huang LW, Kwok YT, Lai TH, Lee SP, Wu HM, Yeh YC: Configuration of the circle of Willis is associated with less symptomatic intracerebral hemorrhage in ischemic stroke patients treated with intravenous thrombolysis. J Crit Care 28: 166-72, 2013

8. De Silva KRD, Silva R, Gunasekera WSL, Jayesekera RW: Prevelence of typical circle of Willis and the variation in the anterior communicating artery: A study of a Sri Lankan population: Annals of Indian Academy of Neurology 12: 157-161, 2009 
9. Eftekhar B, Dadmehr M, Ansari S, Ghodsi M, Nazparvar B, Ketabchi E: Are the distributions of variations of circle of Willis different in different populations? Results of an anatomical study and review of literature. BMC Neurology 6: 1-9, 200 6

10. Fawcett E, Blachford JV: The circle of Willis: An axamination of 700 specimens. J Anat Physiol. 40: 63-70, 1905

11. Fisher CM: The Circle of Willis: Anatomical Variations. Vasc Dis 2: 99-105, 1965

12. Grand W: The anatomy of the brain, by Thomas Willis. Neurosurgery 45: 1234-1237, 1999

13. Hillen B: The variability of the Circulus arteriosus (Willisii): Order or Anarchy? Acta Anat 129: 74-80, 1987

14. Kamath S: Observations on the length and diameter of vessels forming the circle of Willis. J Anat 133: 419-423, 1981

15. Kapoor K, Singh B, Dewan LIJ: Variations in the configuration of the circle of Willis. Anatomical Science International 83: 96-106, 2008

16. Kayambe KNT, Sasahara M, Hazama F: Cerebral aneurysms and variations in the circle of Willis. Stroke 15: 846-850, 1984

17. Lazorthes G, Gouaze A, Santini JJ, Lazorthes Y, Laffont J: Le modelage du polygone de Willis. Neurochirurgie 17: 361-378, 1971 (In French)

18. Lazorthes G, Gouaze A, Santini JJ, Salamon G: The arterial circle of the brain (circulus arteriosus cerebri). Anatomia Clinica 1: 241257,1979

19. Milencovic Z, Vucetic R, Puzic M: Asymmetry and anomalies of the circle of Willis in fetal brain. Surg Neurol 24: 563-570, 1985

20. Miyazawa N, Shinohara T, Yamagata Z: Association of incompleteness of the anterior part of the circle of Willis with the occurrence of lacunes in the basal ganglia. Eur J Neurol 18:1358-60, 2011
21. Orlandini GE, Ruggiero C, Orlandini SZ, Gulisano M: Blood vesse size of circulus arteriosus cerebri (Circle of Willis): A statistical research on 100 human subjects. Acta Anat 123: 72-76, 1985

22. Osborn AG: Diagnostic cerebral angiography. 2nd ed. Philadelphia: Lippincott Williams Wilkins, 1999

23. Overbeeke JJV, Hillen B, Tulleken CAF: A comparative study of the circle of Willis in fetal and adult life. The configuration of the posterior bifurcation of the posterior communicating artery. J Anat 176: 45-54, 1991

24. Padget DH: The circle of Willis. Its embriyology and anatomy. In: Dandy WE (ed), Intracranial arterial aneurysms. NY: Comstock publishing Co, 1947: 67-90

25. Rengachary SS, Xavier A, Manjila S, Smerdon U, Parker B, Hadwan S, Guthikonda M: The legandry contributions of Thomas Willis (1621-1675): The arterial circle and beyond. J Neurosurg 109: 765-775, 2008

26. Riggs HE, Rupp C: Variation in form of circle of Willis. Arch of Neurol 8: 24-30, 1963

27. Saeki N, Rhoton AL: Microsurgical anatomy of the upper basilar artery and posterior circle of Willis. J Neurosurg. 46: 563-578, 1977

28. Seydel HG: The diameters of the cerebral arteries of the human fetus. Anat Rec 150: 79-88, 1964

29. Wilson G, Riggs HE, Rupp C: The pathologic anatomy of ruptured cerebral aneurysms. J Neurosurg 11: 128-134, 1954

30. Yasargil MG: Microsurgical anatomy of the basal cisterns and vessels of the brain. Microneurosurgery I. Stuttgart-New York: George Thieme Verlag, 1984

31. Zeal AA, Rhoton AL: Microsurgical anatomy of the posterior cerebral artery. J Neurosurg 48: 534-559, 1978 